\title{
O CONSUMO E OS RESÍDUOS SÓLIDOS NOS DOCUMENTOS DA EDUCAÇÃO INFANTIL
}

\author{
Natália Teixeira Ananias Freitas, Fátima Aparecida Dias Gomes Marin \\ Universidade Estadual Paulista - UNESP, Programa de Pós-Graduação em Educação, Presidente Prudente, SP. Email: \\ nathyteixeira@hotmail.com.Agência Financiadora: CAPES
}

\begin{abstract}
RESUMO
Este artigo apresenta parte das análises da pesquisa de Doutorado em andamento intitulada "Educação Ambiental, Consumo e Resíduos Sólidos no contexto da Educação Infantil: um diálogo necessário", pertencente ao PPGE - FCT/UNESP, Pres. Prudente(SP). A motivação da pesquisa é discutir a formação de professores e suas práticas pedagógicas diante da Educação Ambiental em Resíduos Sólidos e Consumo no contexto da Educação Infantil. A metodologia é baseada na abordagem qualitativa, do tipo "estudo de caso". Enfatizamos aqui os dados referentes as análises de alguns documentos oficiais para a área da Educação Infantil, especificamente as discussões sobre Consumo e Resíduos Sólidos nestes materiais. Constatamos lacunas nos documentos, no que se refere a abordagem dos temas Consumo e Resíduos Sólidos para os trabalhos na Educação Infantil. Faz-se necessário um aprofundamento maior nas discussões, considerando a importância da Educação Ambiental para a formação da criança e o trabalho docente.

Palavras-chave: Consumo, Resíduos Sólidos, Educação Ambiental, Educação Infantil, Documentos Oficiais
\end{abstract}

\section{THE CONSUMPTION AND SOLID WASTE IN THE DOCUMENTS OF CHILD EDUCATION}

\begin{abstract}
This article presents part of the analysis of the PhD research in progress entitled "Environmental Education, Consumption and Solid Waste in the context of Early Childhood Education: a necessary dialogue", belonging to PPGE - FCT / UNESP, Pres. Prudente (SP). The motivation of the research is to discuss teacher training and its pedagogical practices regarding Environmental Education in Solid Waste and Consumption in the context of Early Childhood Education. The methodology is based on the qualitative approach, of the "case study" type. We emphasize here the data referring to the analysis of some official documents for the area of Early Childhood Education, specifically the discussions on Consumption and Solid Waste in these materials. We note gaps in the documents, regarding the approach of the themes Consumption and Solid Waste for the work in Early Childhood Education. There is a need for a greater deepening in the discussions, considering the importance of the Environmental Education for the formation of the child and the teaching work.
\end{abstract}

Keywords: Consumption, Solid Waste, Environmental Education, Early Childhood Education, Official Documents 


\section{INTRODUÇÃO}

Este artigo apresenta as primeiras análises realizadas com a pesquisa de doutorado em andamento intitulada "Educação Ambiental, Consumo e Resíduos Sólidos no contexto da Educação Infantil: um diálogo necessário", que possui como motivação discutir a formação de professores e suas práticas pedagógicas diante da Educação Ambiental em Resíduos Sólidos no contexto da Educação Infantil. Por meio desta pesquisa, pretende-se efetuar reflexões a respeito da formação inicial e continuada dos docentes que trabalham na Educação Infantil e investigar suas práticas pedagógicas referentes ao tema Consumo e Resíduos Sólidos. Temos a intenção de contribuir com a qualificação dessas práticas.

Os apontamentos metodológicos que estão sendo utilizados na pesquisa dizem respeito a abordagem qualitativa, conforme Bauer e Gaskell (2002) e Demo (2005). Para a coleta de dados, destacamos os apontamentos da pesquisa do tipo "estudo de caso", conforme Severino (2007). A coleta de dados será realizada por meio de pesquisa bibliográfica, análise documental e aplicação de entrevistas semi-estruturadas, o que levará a realização de um diagnóstico e análise de como acontece a Educação Ambiental em Resíduos Sólidos no contexto da Educação Infantil em Presidente Prudente.

Estamos inseridos em uma Sociedade de Consumo, que adquire bens, consome materiais, produtos, serviços e recursos naturais. Cabe a nós refletirmos sobre o que estamos fazendo com relação a utilização abusiva dos recursos naturais, ao descarte e destino dos resíduos/lixo e aos impactos ambientais gerados desde a extração da matéria-prima para fabricação dos produtos até a decomposição dos resíduos/lixo no meio ambiente.

Portilho (2005) enfatiza que a Sociedade do Consumo na qual fazemos parte colabora para a disseminação de uma Cultura do Consumo, que induz os indivíduos a consumirem cada vez mais o que é disponibilizado pelo mercado. Dificilmente são realizadas reflexões sobre a origem dos produtos, a necessidade ou não de se possuir um determinado objeto, as matérias primas que compõem o objeto, a produção de resíduos sólidos ao final do processo e sobre o destino desses resíduos e os possíveis impactos ambientais decorrentes.

Consideramos oportuno que a criança compreenda todo o ciclo dos produtos, desde a extração da matéria prima até as consequências do descarte no meio ambiente. A modificação de nossos posicionamentos a respeito do consumo e da produção e descarte de resíduos sólidos é essencial.

Os Resíduos Sólidos são o resultado do consumo exercido em sociedade, bem como as "sobras" de uma atividade humana. São pertinentes ações que visem a redução do consumo de bens e materiais para que sejam produzidos cada vez menos resíduos sólidos e que os resíduos sejam tratados e reaproveitados, evitando maiores danos ambientais.

Diante deste contexto, acreditamos que as instituições de Educação Infantil possam criar situações para que a criança, desde pequena, compreenda o que pode fazer para colaborar com a redução do consumo de materiais poluentes no seu contexto vivido e sabia realizar o descarte seletivo.

É fundamental uma Educação Infantil que valorize o ambiente em que a criança está inserida e proporcione atividades e vivências que levem a aquisição de hábitos, valores, saberes e atitudes em prol das questões ambientais. Para tanto, é necessário também à formação de profissionais e professores da Educação Infantil que atendam a esta necessidade apontada pela sociedade em que vivemos, ou seja, um contexto social, político e educacional que requer mais atenção com relação ao meio ambiente.

O objetivo deste trabalho é apresentar as análises realizadas em três documentos oficiais do MEC para a área de Educação Infantil: Parâmetros Nacionais de Qualidade para a Educação Infantil - Vol.1 (BRASIL, 2006a) e Vol. 2 (BRASIL, 2006b); Referencial Curricular Nacional para a Educação Infantil - Conhecimento de Mundo, Vol. 3 (BRASIL, 1998) e Diretrizes Curriculares 
Nacionais para a Educação Infantil (BRASIL, 2010). Realizamos uma leitura atenta dos documentos para identificar se os mesmos mencionam o tema Consumo e Resíduos Sólidos em seu contexto e as considerações a respeito da Educação Ambiental para a Educação Infantil.

\section{METODOLOGIA}

A pesquisa está sendo realizada na Rede Municipal de Ensino de Presidente Prudente (SP), mais precisamente com os Coordenadores Pedagógicos da área de Educação Infantil da Secretaria Municipal de Educação (SEDUC) e com os docentes que atuam nas salas de Pré-Escola inseridas nas Escolas de Educação Infantil do município.

A metodologia empregada neste estudo é de natureza qualitativa, conforme os apontamentos de Bauer e Gaskell (2002) e Demo (2005). Para a coleta de dados, utilizamos os fundamentos da pesquisa do tipo "estudo de caso", de acordo com Severino (2007), o que viabiliza a interpretação e análise de dados qualitativos.

Os instrumentos de coleta de dados são os questionários com docentes que atuam em salas de pré-escola a respeito das concepções e práticas pedagógicas sobre Educação Ambiental, consumo e Resíduos Sólidos e entrevistas semi-estruturadas com os Coordenadores Pedagógicos da SEDUC para compreender a estrutura curricular proposta para a Educação Infantil do município e obter informações sobre a incidência da Educação Ambiental nas práticas das escolas.

Neste momento da pesquisa estamos realizando a análise documental de publicações federais, estaduais e municipais a respeito da Educação Infantil, Educação Ambiental em Resíduos Sólidos e consumo. Assim sendo, apresentamos neste artigo as primeiras considerações sobre esses documentos.

Salientamos que esta pesquisa possui aprovação do Comitê de Ética em Pesquisa da FCT/UNESP, conforme parecer consubstanciado, CAAE: 52627515.1.0000.5402.

\section{RESULTADOS}

As análises aqui apontadas revelam a necessidade de ampliação das discussões sobre o Consumo e os Resíduos Sólidos no contexto da Educação Infantil, principalmente nos documentos oficiais. Nos documentos apresentados neste artigo constatamos uma fragilidade das publicações diante da abordagem de questões ambientais, especificamente no que diz respeito ao tema Resíduos Sólidos/Consumo.

O Referencial Curricular Nacional para a Educação Infantil - Conhecimento de Mundo, Vol.3 (BRASIL, 1998) apresenta uma área correspondente às questões da natureza, a criança e sociedade, o que ilustra a importância da área para a formação da criança inserida na Educação Infantil e que deveria fazer parte especificamente dos outros documentos oficiais também. Contudo, não traz discussões específicas sobre Consumo e Resíduos na Educação Infantil.

As Diretrizes Curriculares Nacionais para a Educação Infantil (BRASIL,2010) e os Parâmetros Nacionais de Qualidade para a Educação Infantil - Vol. 1(BRASIL, 2006a) e Vol.2 (BRASIL, 2006b) não abordam a Educação Ambiental na Educação Infantil, especificamente para o tema Consumo/Resíduos.

\section{DISCUSSÃO}

Avaliamos três documentos oficiais da Educação Infantil: Parâmetros Nacionais de Qualidade para a Educação Infantil - Vol. 1 e 2 (BRASIL, 2006); Referencial Curricular Nacional para a Educação Infantil - Conhecimento de Mundo, Vol. 3 (BRASIL, 1998) e Diretrizes Curriculares Nacionais para a Educação Infantil (BRASIL, 2010), com o intuito de compreender ainda mais as discussões sobre Educação Ambiental e Educação Infantil.

Os Parâmetros Nacionais de Qualidade para a Educação Infantil (BRASIL, 2006) foram lançados no ano de 2006, por meio da Secretaria de Educação Básica do MEC, Coordenação Geral 
de Educação Infantil e o Departamento de Políticas de Educação Infantil e do Ensino Fundamental. Essa publicação dispõe 2 volumes, com o intuito de apresentar referências de qualidade para os sistemas educacionais brasileiros, bem como apontar caminhos que atendam as particularidades de cada Instituição de Educação Infantil no país.

O primeiro volume (BRASIL, 2006a) contempla uma discussão teórica sobre as concepções de criança e de Pedagogia na Educação Infantil, além de debates sobre a qualidade da Educação e da Educação Infantil; resultados de pesquisas sobre os estabelecimentos de Educação Infantil e o desenvolvimento das crianças, e o significado de qualidade na perspectiva da legislação e da atuação dos órgãos oficiais no Brasil.

Percebe-se neste volume, apontamentos ligados a área ambiental, merecem destaque, tais como: "[...] o ser humano é parte da natureza e não seu dono e senhor absoluto[...]"(TIRIBA apud BRASIL, 2006a, p. 18); aprender a conhecer o mundo da natureza; repercussões das ações humanas no mundo; preservação e respeito a biodiversidade; atividades sensoriais com a natureza nas Instituições de Educação Infantil; incentivo as crianças ao aprofundamento sobre os conhecimentos a respeito da natureza e da cultura, com estratégias pedagógicas. No entanto, nenhuma dessas discussões menciona especificamente os temas Consumo e Resíduos Sólidos na Educação Infantil.

O segundo volume (BRASIL, 2006b) apresenta as competências e características das Instituições de Educação Infantil a partir de definições legais. É considerado como um Sistema Educacional de Qualidade aquele que respeita a legislação vigente, possui papéis definidos, competências delimitadas, apoio financeiro, administrativo e pedagógico às escolas vinculadas. (BRASIL, 2006b).

Encontramos neste segundo volume também os parâmetros em nível federal, estadual e municipal para a Educação Infantil; uma caracterização das Instituições de Educação Infantil no Brasil e os Parâmetros Nacionais de Qualidade para as Instituições de Educação Infantil propriamente ditos, divididos em 16 sessões. É importante consideramos que, dentro desses parâmetros, destacamos o número 12.9, que define que "[...] as professoras de Educação Infantil realizam atividades nas quais bebês e crianças sejam desafiados a ampliar seus conhecimentos a respeito do mundo da natureza e da cultura".(BRASIL, 2006b, p.40).

Percebemos que, o volume 1 (BRASIL, 2006a) apresenta questões ambientais por meio de discussões teóricas; já o volume 2 (BRASIL, 2006b) contempla parâmetros específicos para a qualidade na Educação Infantil. Contudo, os apontamentos encontrados nestes dois volumes não apresentam especificamente a temática Consumo/Resíduos Sólidos para a área de Educação Infantil, o que leva a uma fragmentação nas discussões que se referem ao meio ambiente, e a Educação Ambiental, de um modo geral.

O segundo documento analisado é o Referencial Curricular Nacional para a Educação Infantil (RCNEI): Conhecimento de mundo-Vol. 3 (BRASIL,1998). Foi criado no ano de 1998 pelo Ministério da Educação, após a promulgação dos Parâmetros Curriculares Nacionais para o Ensino Fundamental (PCN).

É composto por três volumes: 1-Introdução; 2 - Formação Pessoal e social; 3Conhecimento de Mundo, sendo que no volume três, denominado "Conhecimento de Mundo", destaca-se o desenvolvimento infantil e as interações que a criança deve ter com o meio social, cultural e principalmente o meio ambiente.

Ao longo deste documento, são realizadas discussões a respeito da criança, a natureza e a sociedade, especificando objetivos, conteúdos, orientações didáticas, organização do espaço, recursos materiais, registros, avaliação, entre outros aspectos, sempre versando para os grupos de crianças de zero a três anos e quatro a seis anos. É proposto que os conteúdos sejam trabalhados por meio de projetos, integrando as dimensões do mundo social e natural. (BRASIL, 1998) 
Percebe-se ainda neste documento (BRASIL, 1998), a presença de discussões sobre a ação do homem na natureza e o seu papel em sociedade, bem como a necessidade de se valorizar as atividades de manutenção e preservação do meio ambiente. Constatamos a possibilidade de inserção do tema Consumo e Resíduos Sólidos a partir do aprofundamento dos assuntos em pauta.

Outro ponto que merece destaque no documento diz respeito ao tópico que trata dos "objetos e processos de transformação" e que indicam a utilização correta dos recursos:

Conhecer o mundo implica conhecer as relações entre os seres humanos e a natureza, e as formas de transformação e utilização dos recursos naturais que as diversas culturas desenvolveram na relação com a natureza e que resultam, entre outras coisas, nos diversos objetos disponíveis ao grupo social que as crianças pertencem [...]. (BRASIL, 1998, p.186)

São evidenciadas também as relações que o homem possui entre seus pares e a natureza, como aponta o tópico "os lugares e suas paisagens", por meio do conteúdo "[...] valorização de atitudes de manutenção e preservação dos espaços coletivos e do meio ambiente". (BRASIL, 1998, p.184). Esses apontamentos dão margem para discussões a respeito do tema Consumo e Resíduos Sólidos.

Por fim, o terceiro documento que analisamos são as Diretrizes Curriculares Nacionais para a Educação Infantil (BRASIL, 2010), elaborada pelo Ministério da Educação e Secretaria da Educação Básica e distribuída para todos os municípios no ano de 2010. É um documento de caráter mandatório que possui como motivação orientar os Sistemas Municipais de Ensino na elaboração de suas políticas públicas locais relacionadas à Educação e Propostas Pedagógicas na Educação Infantil.

Encontramos neste documento as principais definições para a Educação Infantil, por meio dos tópicos: Educação Infantil, criança, currículo, proposta pedagógica; princípios e objetivos para a Proposta Pedagógica; como deve acontecer a organização do espaço, tempo e materiais na Educação Infantil; as Propostas Pedagógicas para a Diversidade, crianças indígenas, infâncias do campo; Práticas Pedagógicas da Educação Infantil; Avaliação na Educação Infantil e a transição da Educação Infantil para o Ensino Fundamental. (BRASIL, 2010)

Destacamos como aspectos positivos do documento (BRASIL, 2010): a menção da criança como um sujeito que constrói sentidos e valores a respeito da natureza por meio da experimentação e vivências entre os pares; apresentação do princípio ético, que cita o meio ambiente, visão de mundo e de conhecimentos plurais na formação da criança; o respeito às formas de vida, o cuidado com os seres vivos e a preservação dos recursos naturais; uma proposta pedagógica que possibilite a criança a construir novas formas de sociabilidade, principalmente com a sustentabilidade do planeta; valorização da infância do campo e das características do meio que as crianças vivem; um currículo que por meio dos eixos de interações e brincadeira incentivem a curiosidade, a exploração e o conhecimento das crianças em relação ao mundo físico, social e à natureza.

Por mais que as Diretrizes Curriculares Nacionais para a Educação Infantil (BRASIL, 2010) apresentem vários aspectos positivos ligados à Educação Ambiental na Educação Infantil, infelizmente não encontramos menção específica a área de Educação Ambiental e o trabalho com o consumo e os Resíduos Sólidos na Educação Infantil. Trata-se de um documento importante a ser considerado e que poderia apresentar um detalhamento maior para a área de meio ambiente e as questões ambientais. 


\section{CONCLUSÃO}

Torna-se essencial a inserção das questões ambientais e da Educação Ambiental no contexto da Educação Infantil, para que nossas crianças possam desde sua formação inicial ter contato com atividades, vivências e discussões que mostrem que todos nós fazemos parte da natureza. É importante que percebam as transformações que o meio sofre ao longo do tempo pela ação do homem e como elas podem contribuir para um meio ambiente sustentável.

Para que essa inserção aconteça de forma efetiva, os documentos oficiais que subsidiam os planejamentos e práticas na Educação Infantil necessitam abordar a temática ambiental, principalmente as questões referentes ao Consumo e Resíduos Sólidos, assegurando a formação inicial das crianças para o meio ambiente e práticas docentes mais comprometidas com a realidade das crianças e a sensibilização por meio da Educação Ambiental.

\section{REFERÊNCIAS}

BAUER, M.W,; GASKELL, G. Pesquisa qualitativa com texto, imagem e som: um manual prático. Petrópolis: Vozes, 2002.

BRASIL. Referencial curricular nacional para educação infantil: Conhecimento de Mundo v.3 Brasília: Ministério de Educação e do Desporto. Secretaria de Educação Fundamental. 1998.

. Parâmetros Nacionais de Qualidade para a Educação Infantil, v.1. Brasília: Secretaria de Educação Básica, 2006a.

. Parâmetros Nacionais de Qualidade para a Educação Infantil, v.2. Brasília: Secretaria de Educação Básica, 2006b.

. Diretrizes curriculares nacionais para Educação Infantil. Brasília: Ministério de Educação e do Desporto. Câmara de Educação Básica do Conselho Nacional de Educação, 2010.

DEMO, P. Metodologia da Investigação em Educação. Curitiba: IBPEX, 2005,186p.

PORTILHO, F. Sustentabilidade Ambiental, consumo e cidadania. São Paulo: Cortez, 2005, 255p.

SEVERINO, A.J. Metodologia do Trabalho Científico. São Paulo: Cortez Editora, 2007,304p. 